\title{
Spontaneous Rupture of Hydatid Cyst of the Liver in Pediatric Age Group Four Rare Cases with Literature Review
}

\author{
Professor Abdulrahman Sulaiman \\ Retired Department of surgery, College of Medicine University of Mosul, Mosul . Iraq \\ Correspondence: sulaimanazmi@gmail.com
}

(Ann Coll Med Mosul 2021; 43 (1):35-41).

Received: 24 ${ }^{\text {th }}$ Dece. 2020; Accepted: $8^{\text {th }}$ Febr. 2021.

\begin{abstract}
Introduction: Hydatid cyst of the liver is usually asymptomatic,diagnosed accidentally or when there is complications such as infection or rupture.Rupture may occur spontaneously or related to trauma. Spontaneous rupture is more seen in endemic areas like Iraq and frequently seen in children.

Method: Four cases with spontaneous rupture of liver hydatid cyst were reported at Mosul Pediatric Surgical Center at AL-KHANSA A Teaching Hospital. They were diagnosed by ultrasound, chest $\mathrm{x}$ - rays and C T Scan. They underwent surgical exploration and removal of the cysts. Post-operative medical treatment with Albendazole were used prophylactly in all of them.

Results: There were three males and one female, their age ranged from 5.5 to 10 years. Their main presentations were abdominal pain, one of them had respiratory symptoms while the forth had allergic reactions. Ultra sound examination was the main tool of diagnosis, chest $\mathrm{x}$-rays was useful in one and C T Scan was needed in two of the cases.Surgical approach to these patients were by laparotomy in three and right lower thoracotomy in one .Removal of the cyst and cleaning of the cavity with antiseptic solution . These four hydatid cysts ruptured at different sites two of them to peritoneal cavity, one to thoracic cavity and one to extra peritoneal space.

Conclusion: Liver H C rupture is a serious complication, it comes in the differential diagnosis of acute abdomen in endemic area .It needs urgent management. It can rupture at any points of liver surface to peritoneal cavity. Rupture can extend to pleura, biliary passages and extra peritoneal space when there is adhesion and erosion of the ectocyst to these structures. Rupture H.C of the liver to pleura can be dealt through thoracotomy approach without opening the abdomen. Extra peritoneal rupture of liver hydatid cyst can be dealt extra peritoneally without opening the peritoneal cavity and without contaminating the peritoneal cavity.
\end{abstract}

Keywords: liver hydatid cyst in children, Spontaneous rupture , Echinococcosis .

$$
\begin{aligned}
& \text { انفجار الكيس المائى للكبد التلقائى لاى الاطفال تسجيل اربع حالات نادرة }
\end{aligned}
$$

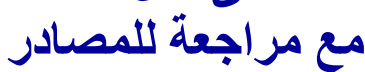

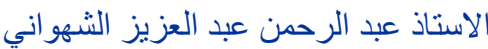

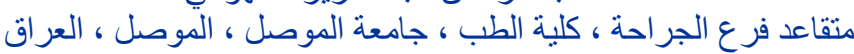

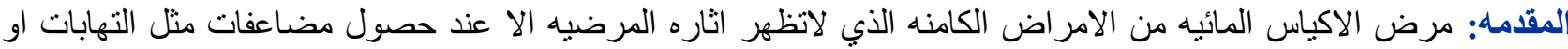

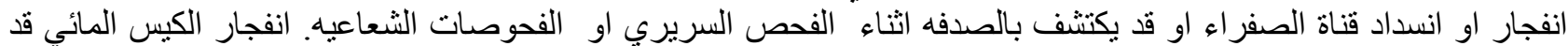

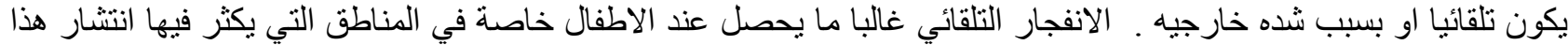
المرض .

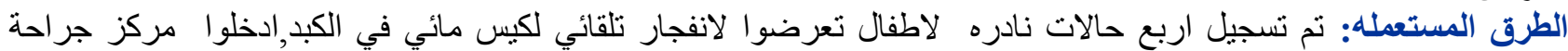

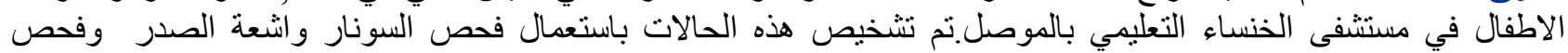

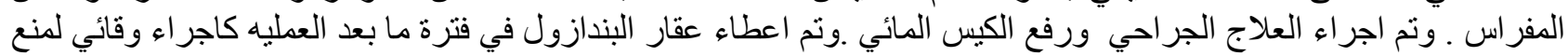
حصول عودة الكبس ثانيه.

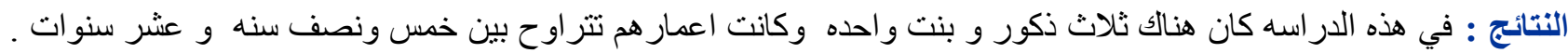

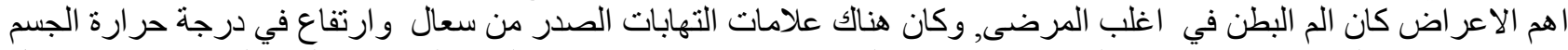
في احد هو لاء المرضى وكان الح الحن المرضى ظهرت عليه علامات حساسيه وطفح جلدي .التشخيص لهذه الحالات التات اعتمد بشكل 


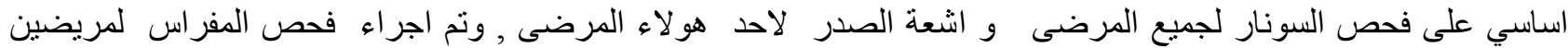

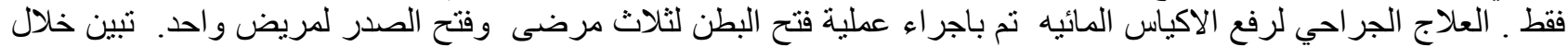

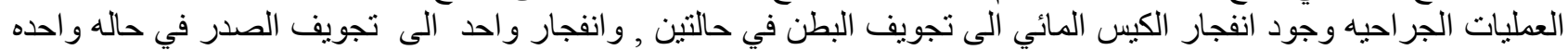

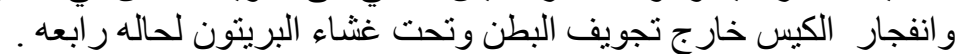

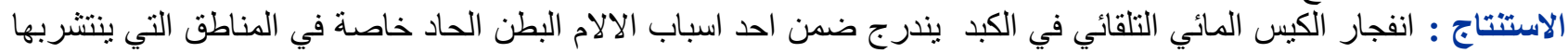

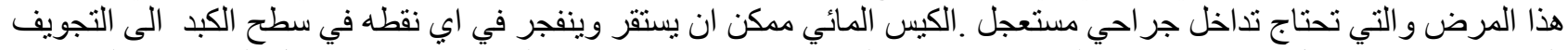

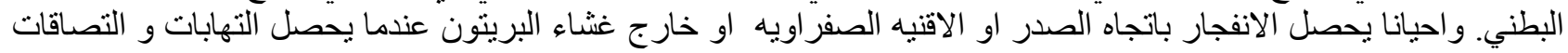

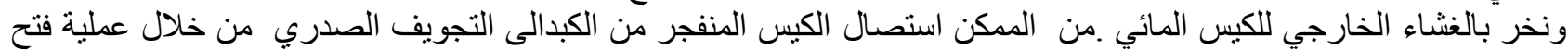

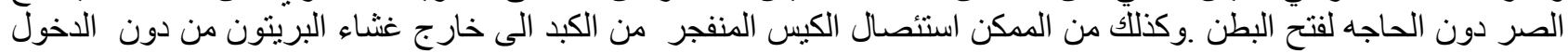

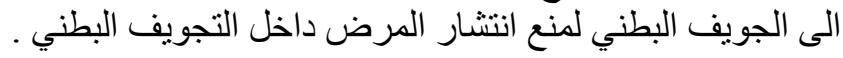

الكلمات المفتاحية : الانفجار التلقائي للكيس المائي , الاكياس المائية عند الاطفال في الكبد , مرض داء الكلب ..

\section{INTRODUCTION}

ydatid cyst is a chronic silent disease, which is usually asymptomatic. It may be discovered accidentally on clinical examination or investigations like $X$-ray, ultrasound or CT $\operatorname{scan}^{1-3}$. It is parasitic infection cause by larval stage of Echinococcus granulosus ${ }^{4,5}$. The Clinical features of this disease depend on many factors, including size and site of the cyst (central or peripheral) and the presence or absence of complications such as infection or rupture. Rupture liver hydatid cyst may occur spontaneously or after trauma ${ }^{6,7}$.

Rupture liver hydatid cyst fall into three categories: contained, communicating and direct ${ }^{8}$. Contained rupture involves only the endocyst without rupture of the ectocyst. Communicating rupture involves tear of the endocyst with escape of content via biliary or bronchial passages that have been incorporated into the ectocyst. Tear of ectocyst and endocyst into the peritoneal or pleural cavity is a direct rupture. . However rupture can cause only minimal symptom or even clinically silent, presenting years later with disseminated intra-abdominal disease. This phenomenon is called secondary echinococcosis ${ }^{9-11}$

Rupture liver hydatid cyst to peritoneal cavity can cause acute abdomen, anaphylaxis and even sudden death ${ }^{12-14}$. Rupture of liver hydatid cyst to pleura may cause pleural or lung paranchymal lesion depending on the degrees of adhesion and inflammation ${ }^{15}$. This inflammation can lead to tissue damage and necrosis that predispose to fistula. The cyst may erode through the diaphragm and rupture into the pleura ، pericardial cavity، lung or bronchi. Bronchobiliary fistula leads to haemptysis and even cyst expectoration ${ }^{15}$. I am reporting four cases of liver hydatid cyst with rare presentation (tab-1).

Table 1. Case summaries

\begin{tabular}{|c|c|c|c|c|}
\hline parameters & Case-1 & Case-2 & Case-3 & Case-4 \\
\hline Age & 10 year & 5.5 year & 7 year & 10 year \\
\hline sex & male & male & female & male \\
\hline $\begin{array}{l}\text { Main } \\
\text { presentation }\end{array}$ & $\begin{array}{l}\text { Cough ,fever,chest } \\
\text { pain and upper } \\
\text { abdominal pain }\end{array}$ & $\begin{array}{l}\text { Sudden severe } \\
\text { upper abdominal } \\
\text { pain with } \\
\text { tenderness }\end{array}$ & $\begin{array}{l}\text { Chronic abdominal } \\
\text { with acute } \\
\text { exacerbation }\end{array}$ & $\begin{array}{l}\text { Allergic reaction, with } \\
\text { anaphylaxis, with } \\
\text { abdominal pain }\end{array}$ \\
\hline Diagnostic Tools & $\begin{array}{c}\text { CX- } \\
\text { rays,U.S,CTSCAN }\end{array}$ & US & US,CT & US \\
\hline $\begin{array}{l}\text { Surgical } \\
\text { approach }\end{array}$ & Right thoracotomy & $\begin{array}{l}\text { Upper transverse } \\
\text { laparotomy }\end{array}$ & $\begin{array}{c}\text { Upper right } \\
\text { subcostal incision }\end{array}$ & $\begin{array}{l}\text { Upper right subcostal } \\
\text { incision }\end{array}$ \\
\hline Operative finding & $\begin{array}{c}\text { Cyst pleural } \\
\text { adhesion with escap } \\
\text { of daughter cyst to } \\
\text { pleura }\end{array}$ & $\begin{array}{l}\text { the ectoocyst } \\
\text { ruptured with } \\
\text { intact endocyst } \\
\text { outside the liver }\end{array}$ & $\begin{array}{c}\text { Adhesion to } \\
\text { parietal peritoneum } \\
\text { with extraperitoneal } \\
\text { rupture }\end{array}$ & $\begin{array}{l}\text { Direct rupture to } \\
\text { peritoneal cavity with } \\
\text { 100s of daughter cyst }\end{array}$ \\
\hline Site of rupture & Falciform ligement & Dome of liver & Lateral surface & Inferior surface \\
\hline $\begin{array}{l}\text { Postoperative } \\
\text { management }\end{array}$ & $\begin{array}{c}\text { Albendazole } 8 \\
\text { weeks }\end{array}$ & $\begin{array}{l}\text { Albendazol } 8 \\
\text { week }\end{array}$ & $\begin{array}{c}\text { Albendazole } 8 \\
\text { weeks }\end{array}$ & $\begin{array}{c}\text { Albendazole 3cycle of } \\
\text { Albendazole for } 28 \\
\text { days then 14days rest } \\
\text { in between }\end{array}$ \\
\hline
\end{tabular}


These cases with hydatid cyst were peripherally situated and the rupture occurred spontaneously, as shown in diagram 1.

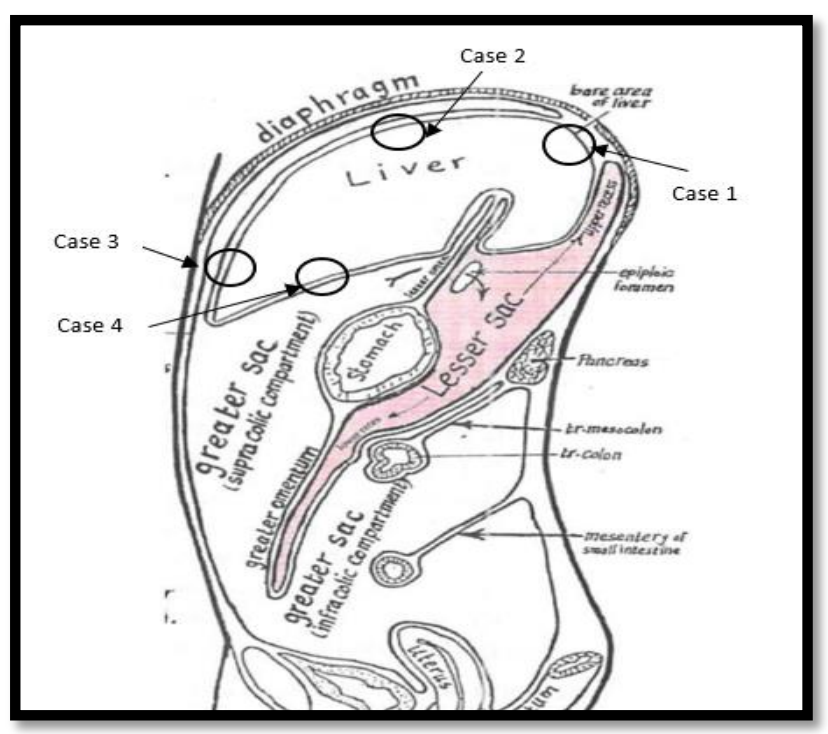

Diagram 1. Site of rupture

\section{CASE NO. 1}

A ten years old boy presented with cough, fever and sweating for the last two week. He also complained of vague upper abdominal pain. He referred pediatric surgical ward from the medical ward, with chest $x$ rays and abdominal ultrasound showing liver hydatid cyst with rounded shadow occupying the base of the right lung. He was put on a course of antibiotics (Ceftriaxone and Metronidazol) without getting any improvement. C.T scan was done and showed infected hydatid cyst of the lung involving the right lower lobe with multiple daughter cysts, with another cyst in the dome of the right lobe of the liver. We decided to deal with chest lesion first.

Exploration through seventh intercostal space revealed communication through the diaphragm between the liver hydatid cyst and inflammatory mass involving the base of the lung consist of multiple daughter cyst with reactionary fluid and pus, Suction and irrigation of the area was performed and finger passed to the cavity of hydatid cyst, removing the main endocyst with good drainage and irrigation and tube drain was left in the cyst cavity. All daughter cysts were removed from the cyst cavity and from pleura. Some of the cysts were adherent to pleura. Washing with normal saline and antiseptic solution (diluted povidin iodine one percent) was performed. Then chest tube was put. Then the thoracotomy wound closed. The patient recovered well and discharge home. Post-operative medical treatment was given with Albendazole for 8 week.

\section{CASE NO. 2}

Five and a half year old boy present with sudden acute abdominal pain and anorexiaq for the last 10 hours without nausea or vomiting. On examination the child look in pain with tense tender abdomen. Ultrasound examination revealed big cyst, measures $14^{\star} 7 \mathrm{~cm}$ lies between the liver and diaphragm. Another cystic lesion is seen in the liver measures $5^{*} 6 \mathrm{~cm}$.

Other investigations including chest $\mathrm{X}$-rays and blood tests were normal.

Emergency exploration was done through upper transverse abdominal incision and hydatid cyst ( measuring about $14^{\star} 7^{\star} 7 \mathrm{~cm}$ ) situated between liver and diaphragm floating unruptured (fig1, 2) with clear tear noticed on the top of the liver dome with cavity that can admit three fingers easily inside without hydatid cyst. The cyst was intact without rupture while the tear is clearly noticed on the liver surface near the dome of the right lobe of the liver, including the ectocyst tissue. The cyst removed and the cavity was mopped and clean with povidine iodine. No bile leak was seen. Plication of the cyst cavity in order to minimise the space. Then peritoneal wash with normal saline and diluted hibitane solution. Then the abdomen was closed with drainage tube left in sub diaphragmatic space. The tube drain was removed after 48 hours and the patient discharge well. Postoperative medical treatment with Albendazole was given for 8 weeks.

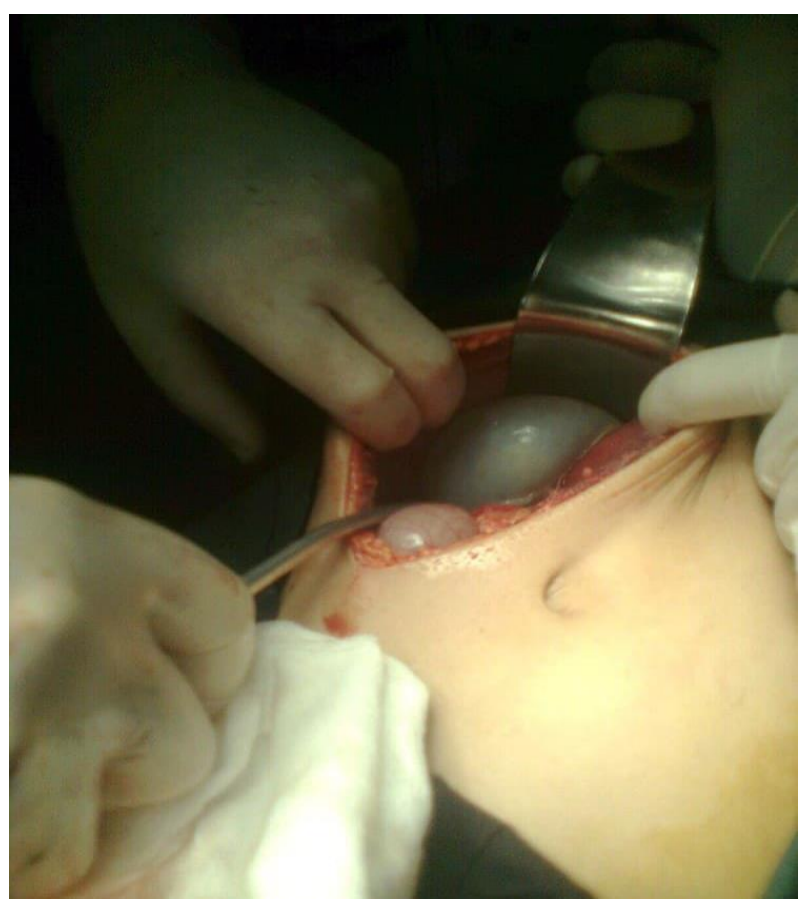

Fig.1 hydatid cyst located under the diaphragm 


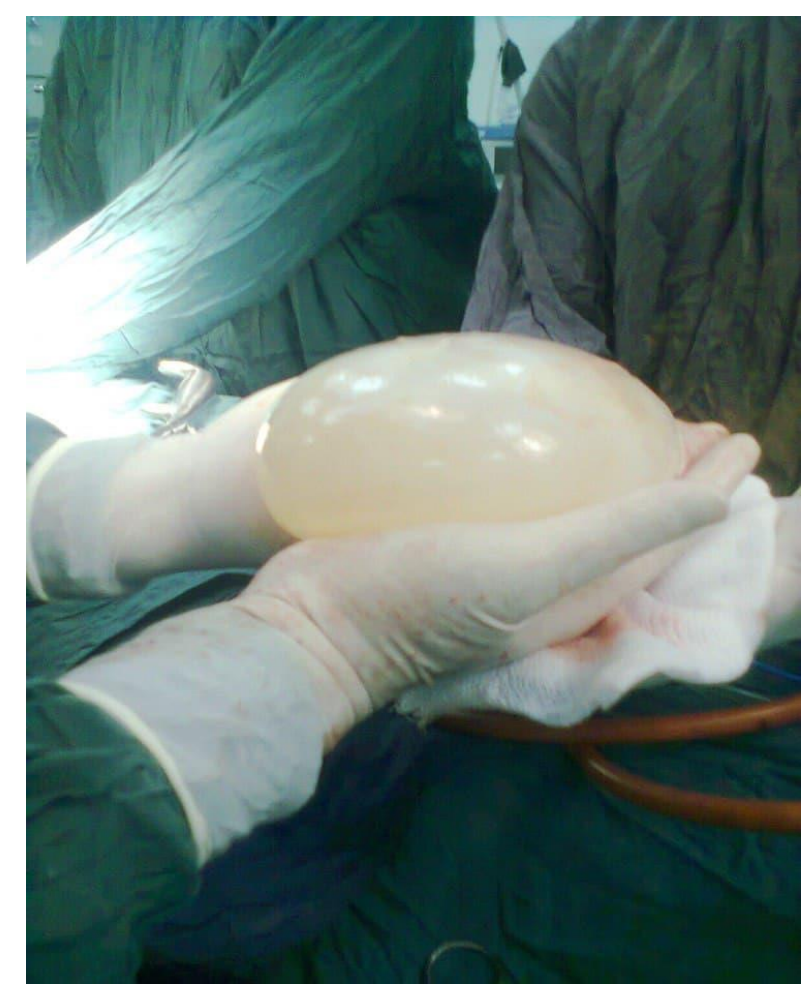

Fig. 2 the cyst removed intact

\section{CASE NO. 3}

Seven years old female was admitted to pediatric surgery center with moderate abdominal pain two months ago. There was no nausea nor Vomiting. There was normal bowel motion. There is no history of fall or trauma. On examination: there was mild to moderate tenderness mainly over the right side of the abdomen with normal bowel sound. Ultrasound examination of the abdomen showed a unilocular hydatid cyst of the liver situated posterolaterally with features of fluid collection on the lateral and anterior abdominal wall. CT scan reveal ruptured hydatid cyst of the liver measure $10^{\star} 8 \mathrm{~cm}$ into the extra peritoneal space extending from the dome downward to pelvis anteriorly and laterally (Fig.3). Other investigations including Chest $X$-rays and Blood tests were normal.

Laparotomy through right sub costal incision, the exterior and internal muscle layers were divided,then while opening the third muscular layer transverse abdominis muscle) before reaching the peritoneum, a cyst containing about $1500 \mathrm{ml}$ of yellowish serous fluid with 100s of daughter cysts was found and aspirated.This cyst was communicated to lateral surface of the liver.There was single liver hydatid cyst which is penetrating the parietal peritoneum to sub- transverse abdominis Then the main ruptured hepatic cyst with its daughter cyst was evacuated without entering peritoneal cavity and the cavity was mopped and cleaned with antiseptic solution (povidone iodine 1percent). A drainage tube was left in the cyst cavity and extraperitoneal space, and good wash with normal saline and antiseptic solution (povidone iodine 1 percent) was done to extraperitoneal space where the fluid was trapped. Then the wound was closed, and the patient had smooth recovery and well on discharge. Albendazole was given for 8 week after surgery to prevent recurrent hydatid cyst.

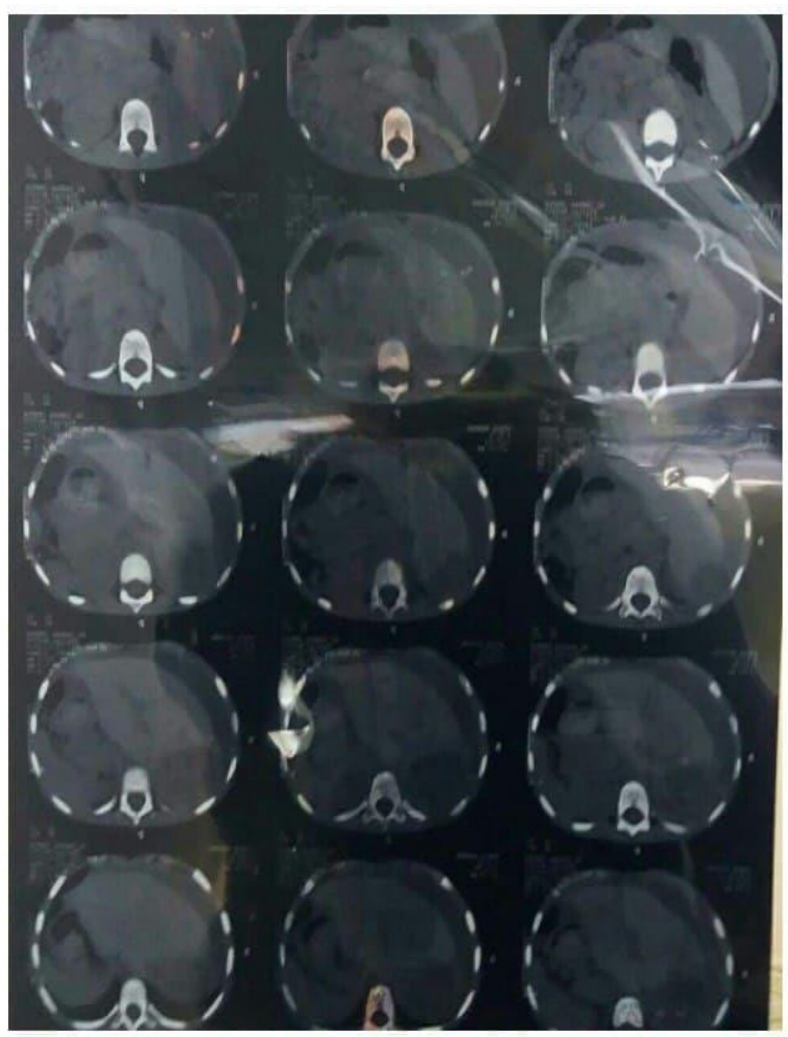

Fig 3. C.T. Scan of the liver and abdominal wall

\section{CASE NO. 4}

A ten years old male admitted to Hammam Al Alil Field Hospital in May 2018 as a case of abdominal pain for observation were the pain was sudden onset, for few hours duration with no history of trauma and the abdomen was soft with right iliac fossa tenderness. He was put under observation, received ceftriaxone antibiotic at admission. During observation period in the medical unit, the patient developed urticaria which increased in severity then anaphylaxis occurred, and the patient referred to Pediatric Hospital as a drug allergy following failure of completely respond to treatment.

He continued his treatment and the patient discharged home after 2 days with no complaint. 
Two weeks later he consulted the field hospital for persistent abdominal pain and attacks of urticaria. The abdomen was soft with right hypochondrial tenderness.

US examination showed free peritoneal fluid collection with sub hepatic cystic lesion at segment 4 of $(3 \times 4 \times 4 \mathrm{~cm})$, with internal septations. Rupture hydatid cyst was suspected, chest X-Ray was normal looking.

Exploration by right subcostal incision done and ruptured hydatid cyst was found at the inferior surface of the liver lateral to the gall bladder with adhesion to the adjacent transverse colon. Hundreds of daughter cysts of $1-2 \mathrm{~mm}$ found all over the peritoneal cavity which were difficult to remove. The main endocyst removed, and wide opening made in the ectocyst wall to prevent collection of fluid later, (Fig 4) with good cleaning with povidone iodine solution.The peritoneal cavity washed with normal saline several times,one wash was with diluted hebitan solution.

The patient did well post operatively and he received 3 cycles of albendazol of 28 days with 14 days rest in between.

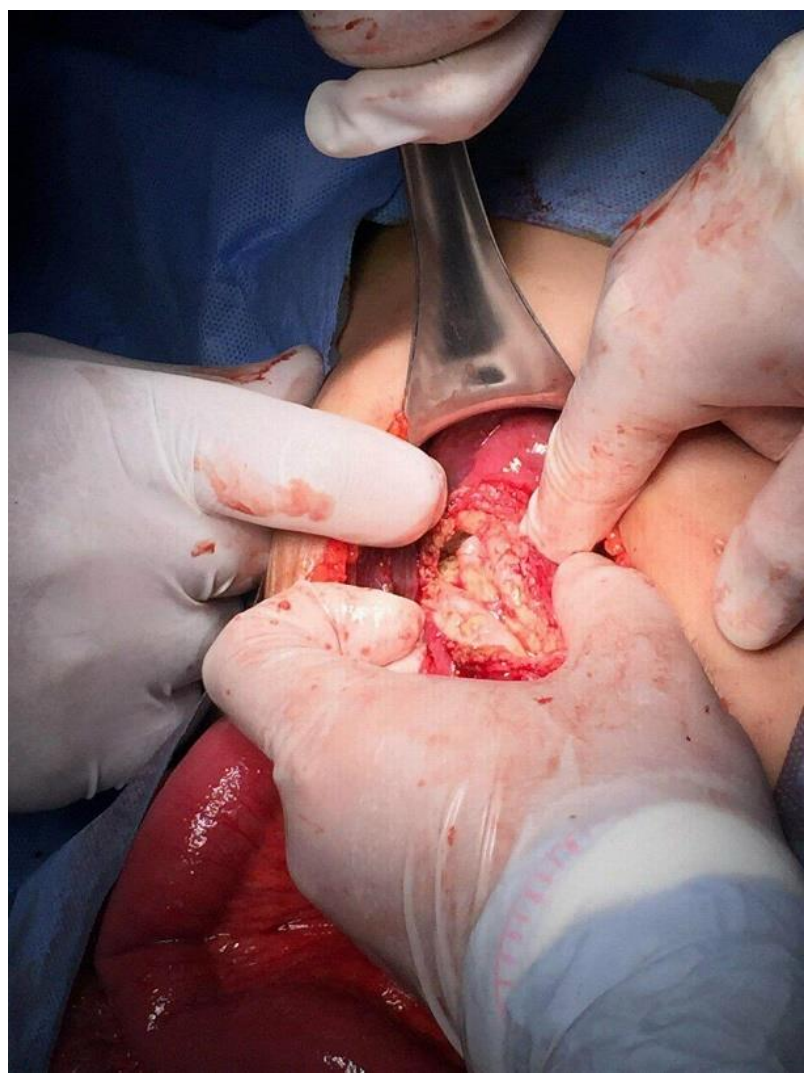

Fig 4. Excision of part of ectocyst

\section{DISCUSSION}

Rupture hydatid cyst is a serious complication with morbidity and mortality. Rupture can be microscopic or macroscopic and can be fatal without surgery ${ }^{12,16,17}$. The cysts may rupture to peritoneal cavity, to pleural space or to biliary passages. Rupture liver hydatid cyst could be spontaneously or after minor or major trauma. A study conducted by Yilmas et. al,. found 22 articles published between 2000-2011about Hydatid cyst rupture after trauma ${ }^{18}$. The most commonly causes includes Road Traffic Accident and fall from high. Hydatid cyst of the liver may remain latent and symptomless for several years. It may discovered accidentally or it become obvious when there is complications such as rupture or infection 19. Adhesion and chronic inflammation can lead to extra peritoneal rupture as in case (no 3 ).

Spontaneous Rupture in those symptomless cases can be amazing and challenging for the surgeon as in our cases. It may mimic other acute abdominal emergency. For this reason it should be included in the differential diagnosis of acute abdomen in endemic areas especially in young patients ${ }^{18}$. The symptoms vary from mild abdominal pain to severe fatal anaphylactic reaction ${ }^{20}$

The main precipitating factor for rupture is sudden increase of pressure of the cystic fluid and there are three predisposing factors: Young age, size more than $10 \mathrm{~cm}$, and superficial location ${ }^{1,2}$. These three factors were found in our patients.

Young age is a risk factor because of the greater activities and liability for trauma and high prevalence of the hydatid cyst in children and adolescent than adult. The age of our patients ranged from 5.5 years to 10 years. Adult patient are not immune of spontaneous rupture ${ }^{21}$

Increase cyst diameter (more than $10 \mathrm{~cm}$ ) in children can lead to increase tension inside the cyst make it more liable for rupture. The rate of cyst growth is variable, ranging from 1 to $5 \mathrm{~cm}$ in diameter per year ${ }^{22}$. Most of our cases they exceed $10 \mathrm{~cm}$ in diameter.

Superficial location is very important risk factor for spontaneous rupture or in relation to mild or trivial trauma. In our cases all of them were peripherally situated and all of them denied any history of trauma or any exertion.

Rupture of liver hydatid cyst into the biliary passages usually occur in those cyst which are centrally situated in the liver. The incidence of rupture into the biliary tree range between $3 \%$ 17\% while in other study it ranged from $5 \%$ _25\% ${ }^{23,24}$ while intra peritoneal rupture is observed in $3.2 \%$ to $16 \%{ }^{25}$ of the cases, while in other study they consider it very rare and it ranges 
between 1\%_8\% 26 and it is occasionally associated with anaphylactic reaction.

Thoracic rupture of liver hydatid cyst result from proximity of hydatid cyst in the liver and the diagragm and are seen in a proximity $0.6 \% \_16 \%$ of cases $^{15}$.

The Clinical finding varies according to the pattern of leak from mild leak to massive leak with bile which can lead to peritonitis. The symptoms will be more severe if there is bile leak or biliary fistula or cyst get infected.

Plain abdomin X-rays is not informative in diagnosis of hydatid cyst of the liver, but it is useful in hydatid cyst of the lung. Ultrasound is widely used as it is inexpensive. CT and MRI is more diagnostic and it can give more information than ultrasound regarding exrahepatic, thoracic and biliary extension. CT scan is not always accessible in our center especially during the night time. Sometimes it is out of use, so we depend on ultrasound. All these cases were dealt with as an emergency.

There were no serious complications postoperatively except there was persistent cavity in the first case which was discovered on routine follow up by serial ultrasound examination which create some concern to parents for possible recurrent hydatid cyst. However there were no recurrence and no serious complication such as cysto-biliary fistula ${ }^{27}$.

Many papers have been published cases of rupture liver hydatid cyst with anaphylaxis or urticaria as main presenting features. We have one case (case no 4) with allergic reaction which was confused with drug reaction. Minor allergic reaction ranged from $16.7 \%$ 25\% while severe anaphylactic reaction was less, ranged from $1 \%$ 12.5\% ${ }^{2,16,28}$.Anaphylactic reaction can occur without clear macroscopic rupture ${ }^{29}$.

\section{CONCLUSION}

Spontaneous rupture of liver hydatid cyst could occur at pediatric age group. It may present as acute or chronic abdominal pain or chest problem. Plain abdomen x-rays, and ultrasound examination is the minimal tool to reach the diagnosis. CT or $\mathrm{MRI}$ if available is more sensitive and informative. Routine laboratory tests are rarely abnormal expect occasional eosinophiliaa Peripheral liver hydatid cyst has less risk of biliary fistula after rupture than those situated in the core or the central part of the liver.

Rupture liver hydatid cyst always need urgent surgery. They can't receive medical treatment preoperatively but they should receive it postoperatively.
It is possible to deal with liver hydatid cyst through the lower thoracotomy wound if the cyst ruptured to pleura and no need to open the abdomen. Extra peritoneal rupture is very rare and it can be dealt with extra peritoneally without contaminating peritoneal cavity.

Anaphylactic reaction in ruptured liver hydatid is not always present. It has been reported only in less than $25 \%$.

\section{REFERENCES}

1.Dirican A, Yilmaz M, Unal B, Tatli F, Piskin T, Kayaalp C, "Ruptured hydatid cysts into the peritoneum: a case series," Eur J Trauma Emerg Surg, 2010;36(4):375-379,.

2. Feleppa C, D'Ambra L, Berti S, Magistrelli P, Sani C, Falco E, "Laparoscopic treatment of traumatic rupture of hydatid hepatic cyst-is it feasible?: a case report," Surg Laparosc Endosc Percutan Tech, 2009;19(4):140-142,.

3. Akbulut $S$ and Ozdemir F. , "Intra peritoneal rupture of hydatd cyst,four case report and literature review.," World Journal of Hepatology , 2019;11(3):318-329.

4. Akbulut S, Senol A, Ekin A, Bakir S, Bayan K, Dursun $M$, "Primary retroperitoneal hydatid cyst: report of 2 cases and review of 41 published cases," Int Surg, 2010;95(3):189-196.

5.Nelson Ivan, Agudelo Higata, Enrico Brunetti, Cindy McCloskey., "Cystic Echinoccosis (mini review)," Journal of Clinical Microbiology, 2016; 54(3):518-523.

6. Lewall D. B. and McCorkell S. J., "Rupture of echinococcal cysts:diagnosis, classifcation, and clinical implications," American Journal of Roentgenology, 1986;146(2):391-394.

7.Sadaf Sabzevari, Alireza Badirzadah, Reza Shahkaram, Mohammed Seyyedin, "Traumatic rupture of liver hydatid cyst into peritoneal cavity of 11 years old boy . A Case report from Iran.," Rev.Soc.Bras.Med.Trop. 2017;50(6).

8.Silvia Greco , Roberto Cannella, Frederca Vernuccio., "Complications of hepatic Echinococcosis: Multimodality imaging approach.," Insights into imaging. 2019;10(1):113.

9.Acharya A N,Gupta Sh, "'Peritoneal hydatidosis" A review of seven cases," Trop Gasrtoentrol, 2009;30(1):pp. 32-42.

10. Cifti I,Yilmaz H, "Hepatic cyst and intraperitoneal free hydatid cyst," Eur J Gen Med, 2012;1(1):50-52.

11. Anass A . Majbar, Mehdi Aalala, Mouna Elalaoui , Farid Sabbah . et al., "Asymptomatic intra peritoneal rupture of hydatid cyst of the liver. Case report .," B M C Res Note, $2014 ; 7: 114$. 
12. Derici H, Tansug T, Reyhan E, Bozdag AD, Nazli O. , "Acute intraperitoneal rupture of hydatid cysts," World J Surg, 2006; 30(10):1879_ 1883.

13. Kök A. N, Yurtman T. and Aydin N. E , "Sudden death due to ruptured hydatid cyst of the liver," Journal of Forensic Sci, 1993;38(4):974-980,.

14. Jedidi M, Mlayeh S, Masmoudi T, Souguir MK,Zemni M."Sudden death due to hydatid cystthirty four medicolegal autopsy cases," Am J Forensic Med Pathol. 2014.35(1):29-33.

15. Derbel F, Ben Mabrouk M, Hamida $\mathrm{MBH}$, Youssef J, Ali AB, Jemni $H$,et. al. Hydatid Cyst of The liver- Diagnosis, Complications and Treatment, London, IntechOpen Limited, 2012.Doi:10.5772/48433.

16. Akcan A, Akyildiz $H$, Artis T, Ozturk A, Deneme MA, Ok E et al., "Peritoneal perforation of liver hydatid cysts: clinical presentation, predisposing factors, and surgical outcome.," World J Surg. 2007; 31, (6):1284-1291.

17. Sumer A, Caglayan K, Altinli E, and Koksal N , "Case report: spontaneous liver hydatid cyst rupture in a child," Israeli Journal of Emergency Medicine. 2009; 9, (1): 13-16.

18. M. Yilmaz, S. Akbulut, A. Kahraman, and S. Yilmaz, "Liver hydatid cyst rupture into the peritoneal cavity afer abdominal trauma: case report and literature review," International Surgery, 2012;97: 239-244,.

19. Velitchkov NG, Losanoff JE, Kjossev KT, Mironov MB. "Life- threatening treatening traumatic rupture of a liver hydatid cyst," Eur Emerg Med, 2001; 8(3):225-228.

20. Erel S, Kilicoglu B, Kismet K, Gollu A, Akkus MA, "Peritoneal hydatid cyst perforation: a rare cause of emergency abdominal surgeries," Adv Ther, 2008;25(9):943-950.

21. Seifeddine B, Amel C, Ghofrane T,Dhouha B, Lassaad G,Rached B , Taher KM. "Spontaneous rupture of hydatid cyst of the liver in the peritoneal cavity with intact proligerous membrane. Case report and literature review.," Pan Afr Med Journal, 2018;30:174. Doi:10.11604/pamg-2018.30.174.15054.

22. P. Moro and P. M. Schantz, "Echinococcosis: a review," International Journal of Infectious Diseases, 2009; 13(2):125-133.

23. Eckert J, Deplazes P , "Bilological Epidemiolgical Clinical Aspect of EchinoccusZoonosis of increasing concern," Clin Microbiol, 2004; 17(1):107-135.

24. A Zaouche et al, "Management of liver hydatid cysts with a large biliocystic fistula: multicenter retrospective study," world J Surg, $2001 ; 25(1): 28-39$.
25. Gulalp B, Koseoglu Z, Toprak N, Satar S, Sebe A, Gokel Y, et al. "Ruptured hydatid cyst following minimal trauma and few signs on presentation," Neth J Med, 2007;65(3):117-118.

26. Kemal Karakaya, "Spontaneous rupture of a hepatic cyst into the peritoneum causing only mild abdominal pain: a case report," World J Gastroenterol, 2007;13(5):806-808.

27. Nasser M. Meazher, Fadhil Abbas Al janabi, Haider Nadum Obaid., "Outcome of biliary fistula after liver hydatid cyst surgery.," Medico-Ligal update, 2020;20(4): 1829- 1835.

28. Unalp H. R, Yilmas Y., Durak E. and Tarcan $E$, "Rupture of liver hydatid cysts into the peritoneal cavity: a challenge in endemic regions," Saudi Med J . 2010. 31(1) : 37-42.

29. De Wispelaere L., Vande Velde S., Schelstraete P., Van Renterghem K., Moerman F., Van Biervliet S., et al. , "Anaphylactic shock as a single persentation of Echinococcus cyst," Acta Gastroenterol Belg . 2011;74( 3): 462-464, 